\title{
Pengaruh On The Job Training Terhadap Kinerja Karyawan (Studi di PT Kereta Api Indonesia Persero Kantor Pusat Bandung)
}

\author{
Intan Widia Permatasari ${ }^{1}$ dan Harmon ${ }^{2 *}$ \\ ${ }^{1}$ Jurusan Administrasi Niaga, Politeknik Negeri Bandung, Indonesia \\ ${ }^{2}$ Jurusan Administrasi Niaga, Politeknik Negeri Bandung, Indonesia
}

\begin{abstract}
:
Nowadays, a company should be able to survive and compete against a changes in the business, therefore companies must be competitive in order to survive from changes that happen. One of actions that company takes to survive and compete is to improve the ability of major assets of the company itself, human resources. Job training in a company is the company's actions to improve the ability of employees to be able perform the duties and obligations as an employee, so the company's objectives will be achieved. One of job training often done by company is onthe-job training. Training the work which is done by the company will have an impact on both the poor level of the employee's performance. This research aims to determine the relationship between on-the-job training and employee performance. In this research, the object is PT Kereta Api Indonesia (Persero) Bandung Head Office which is a state-owned company engaged in the field of land transportation services. To know the relationship of both, the research method that is used is quantitative with interview techniques, questionnaires, literature, and calculations using SPSS for testing the hypothesis that using Pearson Product Moment correlation analysis, simple regression analysis, and test $R$ square.
\end{abstract}

Keywords: employee performance, job training, on-the-job training, PT KAI

\section{PENDAHULUAN}

Meningkatnya persaingan di dunia bisnis, mendorong suatu perusahaan menyesuaikan diri agar bertahan dan bersaing dalam menjaga kelangsungan bisnisnya. Salah satu kunci utama perusahaan untuk terus bertahan ditentukan oleh sumber daya manusia yang dimiliki oleh perusahaan tersebut. Berdasarkan penelitan yang dilakukan oleh Erlinda, Bambang, dan Arik (2014), sumber daya manusia merupakan salah satu aset berharga yang dimiliki oleh perusahaan karena berperan penting untuk pencapaian tujuan perusahaan yang telah ditentukan sebelumnya.

*Email korespondensi:

muhammadharmon@gmail.com
Usaha perusahaan dalam meningkatkan kualitas sumber daya manusia dilakukan melalui pelatihan kerja. Pelatihan kerja memberikan kesempatan bagi karyawan untuk mengembangkan keahlian dan kemampuan dalam bekerja sehingga keahlian yang dimiliki mampu membantu karyawan dalam melaksanakan pekerjaannya. Adanya program pelatihan diharapkan karyawan akan memahami dan melaksanakan fungsinya di organisasi dimana karyawan tersebut bekerja.

Agar program pelatihan mampu berjalan secara efektif dan efisien, perusahaan akan memilih metode pelatihan yang akan digunakan oleh perusahaan sesuai dengan kebutuhan perusahaan. Salah satu metode pelatihan kerja yang banyak digunakan oleh perusahaan adalah metode on 
the job training dimana pelatihan tersebut langsung dilakukan di tempat kerja dengan diawasi oleh supervisor.

Atan, Raghavan dan Mahmood (2015) menyatakan bahwa karyawan yang telah melakukan pelatihan kerja, efektifitas dari pelatihan tersebut akan diikuti oleh perilaku karyawan ketika melakukan suatu pekerjaan. Artinya, jika karyawan mengikuti program pelatihan yang diadakan oleh perusahaan maka akan berdampak positif terhadap perilaku karyawan ketika bekerja atau dapat dikatakan bahwa akan terjadinya

peningkatan kinerja dari karyawan yang telah melakukan pelatihan. Karyawan yang well-trained akan memiliki tingkat motivasi kerja dan moral kerja yang tinggi karena mereka merasa bahwa perusahaan telah berinvestasi pada kemampuan dan perkembangan karyawan itu sendiri.

Kinerja karyawan merupakan hal penting dalam meningkatkan produktivitas karyawan. Hal ini dipengaruhi oleh pengetahuan, keterampilan, kompetisi yang dimiliki dan sikap atau perilaku yang dimiliki oleh karyawan. Berdasarkan hasil pengamatan dan wawancara yang dilakukan penulis ketika melaksanakan survey lapangan selama 2 bulan di PT Kereta Api Indonesia (Persero) Kantor Pusat Bandung, diadakannya pelatihan kerja terkait dengan kinerja karyawan yang belum optimal. Hal tersebut terlihat ketika pegawai belum mampu menyelesaikan tugas dengan tepat waktu sehingga menghambat proses operasional perusahaan.

Berdasarkan tabel 1.1, dapat terlihat bahwa dimulai dari bulan Januari 2016 hingga bulan April 2016 ketepatan waktu operasional mengalami penurunan dan pada bulan Mei dan Juni 2016 mengalami kenaikan kemudian mengalami penurunan kembali pada bulan Juli hingga September. Tetapi pada bulan Oktober hingga Desember mengalami penurunan pula yang tidak sesuai dengan waktu yang telah ditentukan.

Permasalahan yang telah disebutkan diatas harus segera diselesaikan agar tidak menghambat dalam mencapai tujuan perusahaan. Penelitian ini diharapkan dapat memberikan manfaat dalam membangun kinerja karyawan pada unit Umum \& IT PT Kereta Api Indonesia (Persero) Kantor Pusat Bandung.

Tabel 1.1 Kinerja Karyawan Unit Umum \& IT

\begin{tabular}{|c|l|c|c|}
\hline \multirow{2}{*}{ NO } & \multirow{2}{*}{ BULAN } & \multicolumn{2}{|c|}{ KETEPATAN WAKTU } \\
\cline { 3 - 4 } & & TARGET & HASIL \\
\hline 1 & Januari & $90 \%$ & $80 \%$ \\
\hline 2 & Februari & $90 \%$ & $85 \%$ \\
\hline 3 & Maret & $90 \%$ & $80 \%$ \\
\hline 4 & April & $90 \%$ & $84 \%$ \\
\hline 5 & Mei & $90 \%$ & $90 \%$ \\
\hline 6 & Juni & $90 \%$ & $90 \%$ \\
\hline 7 & Juli & $90 \%$ & $85 \%$ \\
\hline 8 & Agustus & $90 \%$ & $88 \%$ \\
\hline 9 & September & $90 \%$ & $80 \%$ \\
\hline 10 & Oktober & $90 \%$ & $85 \%$ \\
\hline 11 & November & $90 \%$ & $80 \%$ \\
\hline 12 & Desember & $90 \%$ & $80 \%$ \\
\hline \multicolumn{2}{|c|}{ Rata-Rata } & $90 \%$ & $84 \%$ \\
\hline \multicolumn{2}{|c|}{ Ke te rangan } & Baik & $\begin{array}{c}\text { Kurang } \\
\text { Baik }\end{array}$ \\
\hline \multicolumn{2}{|l}{} \\
\end{tabular}

Sumber: Unit Umum \& IT

Fenomena tersebut melatarbelakangi penulis untuk melakukan penelitian di PT Kereta Api Indonesia (Persero) Kantor Pusat Bandung dengan mengambil judul "Pengaruh On The Job Training Terhadap Kinerja Karyawan (Studi di PT Kereta Api Indonesia (Persero) Kantor Pusat Bandung)"

\section{KAJIAN LITERATUR On The Job Training}

Program pelatihan tidak bisa dihilangkan dalam suatu perusahaan karena kaitannya dengan kinerja yang akan dihasilkan oleh karyawan. on the job training adalah metode pelatihan yang dilakukan langsung di tempat kerja dimana karyawan di tempatkan sesuai dengan jabatan mereka masing- masing dengan tujuan untuk mengenalkan secara langsung pada trainee tentang seluk-beluk tugas tersebut di bawah bimbingan pengawas atau supervisor (Swasto (2011:67), Noe (2013:263), dan Darodjat (2015:79)). 
Umumnya, on the job training diberikan untuk karyawan yang baru direkrut. Namun tidak menutup kemungkinan jika diberikan kepada karyawan lama yang bertujuan sebagai dasar pengambilan keputusan untuk promosi atau pemberian penghargaan.

Menurut Widodo (2015:99-101) ada berbagai macam metode yang digunakan dalam on the job training yaitu:

1. Rotasi Jabatan. Melibatkan perpindahan karyawan dari satu pekerjaan ke pekerjaan lainnya.

2. Latihan Intruksi Pekerjaan. Digunakan dengan memberikan petunjuk pengerjaan secara langsung pada pekerjaan.

3. Magang. Proses belajar dari seorang atau beberapa orang yang lebih berpengalaman.

4. Coaching. Bimbingan dan pengarahan yang diberikan kepada karyawan dalam pelaksanaan kerja rutin mereka.

Metode on the job training yang digunakan di PT Kereta Api Indonesia (Persero) Kantor Pusat Bandung adalah rotasi jabatan, latihan intruksi pekerjaan dan coaching. Selain untuk meningkatkan kinerja dan produktivitas karyawan, pelatihan juga memiliki beberapa manfaat lainnya yaitu untuk memenuhi tuntutan pekerjaan sekarang, untuk memenuhi tuntutan jabatan lain, untuk memenuhi tuntutan perubahan (Swasto, 2011:65).

Untuk mengukur keberhasilan dari suatu program pelatihan dapat dilihat melalui beberapa hal (Mangkunegara, 2010 dan Mathis \& Jackson (2006)) yaitu:

1. Penyampaian program pelatihan

2. Metode pelatihan

3. Tujuan pelatihan

4. Kualifikasi pelatih

\section{Kinerja Karyawan}

Kinerja merupakan serangkaian aktivitas dalam suatu proses kerja oleh seseorang atau sekelompok orang dimana hasil kerja tersebut sesuai dengan standar dan kriteria yang ditentukan. Kinerja juga merupakan hasil dari suatu pekerjaan yang dihasilkan dari tingkat kemampuan yang dimiliki karyawan dalam usahanya menyelesaikan tugas- tugas yang diberikan kepadanya (Afshan et al. dalam Hafeez (2015:53), Hasibuan (2012:65), Gomes (2000)).

Menurut Timpe (2002:105) faktor yang mempengaruhi kinerja karyawan adalah sebagai berikut:

1. Motivasi

2. Kejelasan pengharapan

3. Kemampuan

4. Lingkungan kerja

Keempat faktor tersebut dapat didapatkan melalui program pelatihan kerja yang dilakukan oleh perusahaan. Sedangkan menurut Kum dan Karodia (2014:82) faktor yang mempengaruhi kinerja karyawan adalah pengalaman, Work-Home balance, hubungan interaksi manajer dan penentuan tujuan. Menurut Dharma (2003:335), Dessler (2009) dan Bernardin \& Russel (2003) indikator dari kinerja karyawan adalah:

1. Kualitas kerja

2. Kuantitas kerja

3. Timeliness

4. Need for Supervision

\section{METODE}

Penelitian ini menggunakan metode deskriptif analisis. Menurut Sugiyono (2012:11), menjelaskan bahwa penelitian deskriptif adalah penelitian yang dilakukan untuk mengetahui nilai variabel mandiri, baik satu variabel atau lebih (independen) tanpa membuat perbandingan, atau menghubungkan antara variabel satu dengan variabel yang lain. Sampel dalam penelitian ini sebanyak 110 orang karyawan unit Umum \& IT PT Kereta Api Indonesia (Persero) Kantor Pusat Bandung. Teknik analisis data yang digunakan adalah:

1. Uji Asumsi Klasik

Uji asumsi klasik yang digunakan adalah uji normalitas. Dalam penelitian ini 
digunakan analisis grafik normal P-Plot dan metode One Sample Kolmogorov-Smirnov. Menurut Ghozali (2013:161), grafik normal P-Plot ini membandingkan distribusi kumulatif dari distribusi normal. Distribusi normal akan membentuk satu garis lurus diagonal dan plotting data residual akan dibandingkan dengan garis diagonal. Jika distribusi data residual normal, maka garis yang menggambarkan data sesunguhnyaakan mengikuti garis diagonalnya.

Konsep dasar dari uji normalitas Kolmogorov Smirnov adalah dengan membandingkan distribusi data (yang akan diuji normalitasnya) dengan distribusi normal baku (Ghozali, 2013:163).

2. Analisis deskriptif

Analisis deskriptif digunakan untuk mendeskripsikan karakteristik penelitian. Data yang diperoleh kemudian diolah dan ditabulasikan dalam bentuk tabel setelah itu dibahas secara deskriptif.

3. Analisis Regresi Linier

Analisis ini digunakan untuk mengetahui pengaruh dua atau lebih variabel bebas secara bersama-sama terhadap variabel terikat yang ditujukan oleh koefisien regresi.

4. Analisis Korelasi Sederhana

Analisis kolerasi sederhana adalah metode statistika yang digunakan unntuk menentukan kuatnya atau derajat hubungan linear antara dua variable atau lebih. Semakin nyata hubungan linear (garis lurus), maka semakin kuat atau tinggi derajat hubungan garis urus antara kedua variable atau lebih.

5. Uji Hipotesis

Uji hipotesis yang digunakan adalah uji t. Uji t ditujukan untuk mengetahui seberapa jauh pengaruh suatu variabel penjelas secara individual dalam menerangkan variasi variabel terikat. Pendapat lainnya dikemukakan oleh Ghozali (2013:98) bahwa uji statistik t menunjukkan seberapa jauh pengaruh satu variabel independen secara individual dalam menerangkan variasi variabel dependen.

\section{HASIL DAN PEMBAHASAN}

\section{Hasil Uji}

\section{Hasil Uji Validitas dan Reliabilitas}

Pengujian validitas dilakukan dengan menghitung korelasi antara masing-masing pernyataan dengan skor total. Analisis ini digunakan untuk mengetahui pernyataan mana yang valid dengan mengacu pada tingkat signifikan sebesar 0,3 (rkritis). Jika $r$ korelasi $\leq 0,3$ maka pernyataan tidak valid, sedangkan jika $\mathrm{r}$ korelasi $>0,3$ maka pernyataan valid (Sugiyono, 2012: 178). Berikut tabel 1 di bawah ini adalah hasil pengujian validitas ke 30 responden.

Tabel 1 Hasil Uji Validitas 30 Responden

\begin{tabular}{|l|c|c|}
\hline \multicolumn{1}{|c|}{ Item } & $\begin{array}{c}\text { Cronbach's } \\
\text { Alpha }\end{array}$ & Keterangan \\
\hline Penyampaian Pelatihan &, 941 & Valid \\
\hline Penyampaian Pelatihan &, 940 & Valid \\
\hline Penyampaian Pelatihan &, 940 & Valid \\
\hline Metode_Pelatihan1 &, 944 & Valid \\
\hline Metode_Pelatihan2 &, 940 & Valid \\
\hline Metode_Pelatihan3 &, 940 & Valid \\
\hline Tujuan_Pelatihan1 &, 941 & Valid \\
\hline Tujuan_Pelatihan2 &, 940 & Valid \\
\hline Tujuan_Pelatihan3 &, 940 & Valid \\
\hline Tujuan_Pelatihan4 &, 940 & Valid \\
\hline Tujuan_Pelatihan5 &, 941 & Valid \\
\hline Tujuan_Pelatihan6 &, 940 & Valid \\
\hline Tujuan_Pelatihan7 &, 940 & Valid \\
\hline Tujuan_Pelatihan8 &, 941 & Valid \\
\hline Kualifikasi_Pelatih1 &, 940 & Valid \\
\hline Kualifikasi_Pelatih2 &, 942 & Valid \\
\hline Kualifikasi_Pelatih3 &, 942 & Valid \\
\hline Kualitas_Kerja1 &, 943 & Valid \\
\hline Kualitas_Kerja2 &, 943 & Valid \\
\hline Kualitas_Kerja3 &, 944 & Valid \\
\hline Kualitas_Kerja4 &, 944 & Valid \\
\hline Kuantitas_Kerja1 &, 944 & Valid \\
\hline Kuantitas_Kerja2 &, 945 & Valid \\
\hline Kuantitas_Kerja3 &, 940 & Valid \\
\hline Kuantitas_Kerja4 &, 943 & Valid \\
\hline Timeliness_1 &, 942 & Valid \\
\hline Timeliness_2 &, 943 & Valid \\
\hline Timeliness_3 &, 942 & Valid \\
\hline Need for Supervision_1 &, 942 & Valid \\
\hline Need for Supervision_2 &, 940 & Valid \\
\hline
\end{tabular}

Berdasarkan data di atas dapat dilihat bahwa nilai $r$ korelasi per item memiliki nilai $>0,3$ yang artinya bahwa pernyataan tersebut valid.

Sedangkan reliabilitas adalah sebuah 
tes dari bagaimana secara konsisten sebuah instrument pengukur mengukur apapun konsep yang diukur (Sekaran dan Bougie, 2013:228). Menurut Weygandt (2006) semakin dekat koefisien keandalan dengan 1,0 semakin baik. Secara umum, keandalan < 0,60 dianggap buruk, keandalan dalam kisaran 0,70 bisa diterima dan $>0,80$ adalah baik. Berikut tabel 2 dan 3 di bawah ini adalah hasil pengujian reliabilitas variabel $\mathrm{X}$ dan $\mathrm{Y}$ ke 110 responden.

Tabel 2 Hasil Uji Reliabilitas Variabel X 110 Responden

\begin{tabular}{|c|c|c|}
\hline $\begin{array}{c}\text { Cronbach's } \\
\text { Alpha }\end{array}$ & $\begin{array}{c}\text { Cronbach's } \\
\text { Alpha Based } \\
\text { on } \\
\text { Standardized } \\
\text { Items }\end{array}$ & $\begin{array}{c}\text { N of } \\
\text { Items }\end{array}$ \\
\hline, 942 &, 941 & 17 \\
\hline
\end{tabular}

Sumber: Data Olah Penulis 2017

Tabel 3 Hasil Uji Reliabilitas Variabel Y 110 Responden

\begin{tabular}{|c|c|c|}
\hline $\begin{array}{c}\text { Cronbach's } \\
\text { Alpha }\end{array}$ & $\begin{array}{c}\text { Cronbach's Alpha } \\
\text { Based on Standardized } \\
\text { Items }\end{array}$ & N ofItems \\
\hline, 826 &, 830 & 13 \\
\hline
\end{tabular}

Sumber: Data Olah Penulis 2017

\section{Hasil Uji Asumsi Klasik}

Maksud dan tujuan dilakukannya pengujian penyimpanan asumsi klasik yaitu untuk mengetahui apakah model regresi yang diperoleh mengalami penyimpangan asumsi klasik atau tidak. Apabila model regresi yang diperoleh mengalami penyimpangan terhadap salah satu asumsi klasik yang diajukan, maka persamaan regresi yang diperoleh tersebut tidak efisien untuk menggeneralisasikan hasil penelitian bukan semata hubungan dari variabel-variabel yang diteliti tetapi ada faktor pengganggu lainnya yang ikut mempengaruhinya, Zulganef (2008:103).

Berikut gambar 1 uji normalitas dengan grafik Normal Probability Plot.

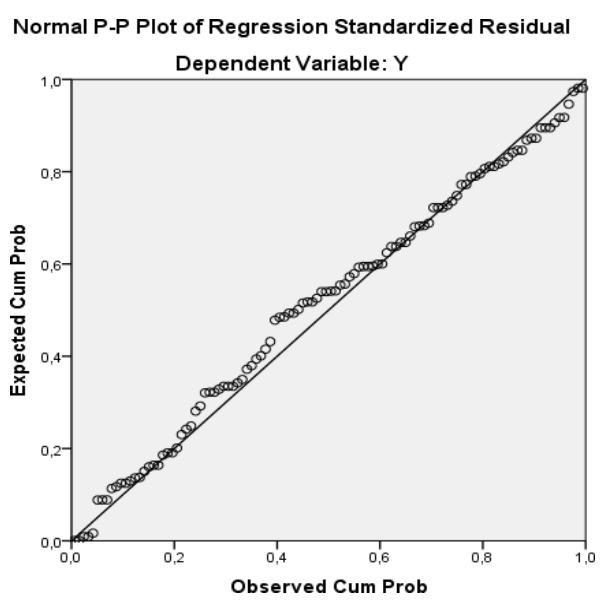

Sumber: Data Olah Penulis 2017

Gambar 1 Normal Probability Plot

Berdasarkan gambar 1 dapat dilihat bahwa titik-titik menyebar di sekitar garis diagonal artinya sebaran data penelitian ini mengikuti pola distribusi normal. Dengan demikian dapat disimpulkan bahwa model regresi on the job training dengan kinerja karyawan memenuhi syarat untuk menjadi model regresi yang baik karena merupakan model regresi memenuhi asumsi normalitas. Untuk memperjelas hasil grafik diatas, maka dilakukan kembali uji normalitas dengan metode uji Kolmogorov- Smirnov. Konsep dasar dari uji normalitas Kolmogorov Smirnov adalah dengan membandingkan distribusi data (yang akan diuji normalitasnya) dengan distribusi normal baku (Ghozali, 2011:163). Sebagaimana terlihat dalam tabel 4 berikut ini.

Tabel 4 One-Sample Kolmogorov-Smirnov Test

\begin{tabular}{|c|c|c|}
\hline $\begin{array}{l}\mathrm{N} \\
\text { Mean }\end{array}$ & & $\begin{array}{r}\text { Unstand. } \\
\text { Residual } \\
110 \\
0 \mathrm{E}-7 \\
\end{array}$ \\
\hline & \begin{tabular}{|l|} 
Std. \\
Deviation \\
\end{tabular} & ,29242540 \\
\hline & Absolute & ,087 \\
\hline $\begin{array}{l}\text { Most Extreme } \\
\text { Differences }\end{array}$ & Positive & ,045 \\
\hline & Negative &,- 087 \\
\hline Kolmogorov-Smirnov Z & & ,915 \\
\hline Asymp. Sig. (2-tailed) & & ,373 \\
\hline
\end{tabular}

Sumber: Data Olah Penulis 2017 


\section{Analisis Deskriptif}

Seperti yang dikemukakan Sugiyono (2012:127), analisis deskriptif adalah memberikan atau menjabarkan suatu keadaan atau fenomena yang terjadi saat ini dengan menggunakan prosedur ilmiah untuk menjawab masalah secara aktual.

Untuk mengukur variabel on the job training dibutuhkan beberapa dimensi yang relevan yaitu Penyampaian Program Pelatihan, Metode yang Digunakan, Tujuan Pelatihan, dan Kualifikasi Pelatih atau Supervisi. Berikut pada tabel 5 adalah hasil analisis deskriptif mengenai variabel on the job training.

Tabel 5 Statistik Deskriptif OJT Descriptive Statistics On The Job Training

\begin{tabular}{|lccc|}
\hline & N & Mean & Std. Deviation \\
\hline $\begin{array}{l}\text { Penyampaian } \\
\text { Program } \\
\text { Pelatihan }\end{array}$ & 110 & 3,78 &, 777 \\
\hline $\begin{array}{l}\text { Metode } \\
\text { Pelatihan }\end{array}$ & 110 & 4,01 &, 575 \\
\hline $\begin{array}{l}\text { Tujuan } \\
\text { Pelatihan }\end{array}$ & 110 & 3,98 &, 606 \\
\hline $\begin{array}{l}\text { Kualifikasi } \\
\text { Pelatih }\end{array}$ & 110 & 4,02 &, 637 \\
\hline OJT & $\mathbf{1 1 0}$ & $\mathbf{3 , 9 6}$ & $\mathbf{, 5 7 5}$ \\
\hline Valid N & 110 & \\
\hline Sumber: Data Olah Penulis 2017 & \\
\hline
\end{tabular}

Berdasarkan hasil analisis data SPSS, keempat dimensi yang terdapat dalam variabel on the job training memiliki nilai mean sebesar 3.96 yang artinya tergolong ke dalam kategori baik/tinggi karena masuk ke dalam interval 3.40-4.20.

Sedangkan untuk mengukur variabel kinerja karyawan dibutuhkan beberapa dimensi yang relevan yaitu kualitas kerja, kuantitas kerja, Timeliness, dan Supervision. Berikut pada tabel 6 adalah hasil analisis deskriptif mengenai variabel kinerja karyawan.
Tabel 6 Statistik Deskriptif Kinerja Karyawan

\begin{tabular}{|lccc|}
\hline & N & Mean & $\begin{array}{c}\text { Std. } \\
\text { Deviation }\end{array}$ \\
\hline Kualitas Kerja & 110 & 4,19 &, 494 \\
\hline Kuantitas Kerja & 110 & 4,28 &, 531 \\
\hline Timeliness & 110 & 4,25 &, 597 \\
\hline Supervisi & 110 & 4,12 &, 570 \\
\hline $\begin{array}{l}\text { Kinerja } \\
\text { Karyawan }\end{array}$ & $\mathbf{1 1 0}$ & $\mathbf{4 , 2 2}$ & $\mathbf{, 4 3 9}$ \\
\hline Valid N & 110 & & \\
\hline
\end{tabular}

Sumber: Data Olah Penulis 2017

Berdasarkan hasil analisis data SPSS, keempat dimensi yang terdapat dalam variabel kinerja karyawan memiliki nilai mean sebesar 4.22 yang artinya tergolong ke dalam kategori sangat baik/sangat tinggi karena masuk ke dalam interval 4.21-5.00.

\section{Analisis Regresi Linier}

Analisis regresi linier digunakan untuk mengetahui besarnya pengaruh antara variabel bebas yaitu on the job training terhadap kinerja karyawan yang dilakukan dengan menggunakan program SPSS.

\section{Persamaan Regresi}

Persamaan regresi digunakan untuk mengetahui bentuk hubungan antara variabel bebas dengan variabel terikat. Didapat model regresi seperti pada tabel 1:

Tabel 7 Hasil Analisis Regresi

\begin{tabular}{|c|c|c|c|c|c|}
\hline \multirow[b]{2}{*}{ Model } & \multicolumn{2}{|c|}{$\begin{array}{c}\text { Unstandardized } \\
\text { Coefficients }\end{array}$} & \multirow{2}{*}{$\begin{array}{c}\text { Standardized } \\
\text { Coefficients } \\
\text { Beta } \\
\end{array}$} & \multirow[b]{2}{*}{$\mathrm{t}$} & \multirow[b]{2}{*}{ Sig. } \\
\hline & B & $\begin{array}{l}\text { Std. } \\
\text { Error }\end{array}$ & & & \\
\hline Constant & 1.951 & .196 & & 9.966 & .000 \\
\hline OJT & .574 & .049 & .748 & 11.71 & .000 \\
\hline
\end{tabular}

Sumber: Data Olah Penulis 2017

Berdasarkan pada tabel didapatkan persamaan regresi sebagai berikut:

$$
\mathrm{Y}=1.951+0.748 \mathrm{X}
$$


Persamaan tersebut memiliki arti jika nilai variabel on the job training naik maka nilai variabel kinerja karyawan juga akan naik.

\section{Koefisien Determinasi}

Nilai $\mathrm{R}$ square digunakan untuk mengetahui besar kontribusi variabel bebas terhadap variabel terikat seperti dalam tabel 4 dibawah ini:

Tabel 8 Koefisien Determinasi dan Korelasi

\begin{tabular}{|c|c|c|r|c|}
\hline Model & $\mathrm{R}$ & $\begin{array}{c}\mathrm{R} \\
\text { Square }\end{array}$ & $\begin{array}{c}\text { Adjusted } \\
\mathrm{R} \\
\text { Square }\end{array}$ & $\begin{array}{c}\text { Std. } \\
\text { Error } \\
\text { of The } \\
\text { Estimate }\end{array}$ \\
\hline 1 & $.748 \mathrm{a}$ & .560 & .556 & .29378 \\
\hline
\end{tabular}

Sumber: Data Olah Penulis 2017

Koefisien determinasi digunakan untuk menghitung besarnya pengaruh atau kontribusi variabel bebas terhadap variabel terikat. Dari analisis diatas diperoleh hasil adjusted $R$ square sebesar 0.556. Yang artinya, $56 \%$ variabel kinerja karyawan dipengaruhi oleh variabel bebas yaitu on the job training. Sedangkan sisanya $44 \%$ variabel kinerja karyawan dipengaruhi oleh variabel lain yang tidak termasuk dalam penelitian ini.

Selain koefisien determinasi juga didapat koefisien korelasi yang menunjukan besarnya hubungan antara variabel bebas terhadap variabel terikat, nilai $\mathrm{R}$ (koefisien korelasi) sebesar 0.748 , nilai korelasi ini menunjukan bahwa hubungan antara variabel bebas dengan kinerja karyawan termasuk dalam kategori sangat kuat karena berada pada interval $+0,70$.

Hubungan antara variabel bebas on the job training dengan kinerja karyawan bersifat positif artinya, jika variabel bebas semakin ditingkatkan maka kinerja karyawan akan mengalami peningkatan.

\section{Pengujian Hipotesis}

Pengujian hipotesis merupakan bagian penting dalam penelitian. Kegunaan utamanya adalah untuk menjawab hipotesis yang dibuat oleh penulis.

\section{Uji T (Parsial)}

Uji t digunakan untuk mengetahui apakah masing-masing variabel bebas secara parsial mempunyai pengaruh yang signifikan terhadap variabel terikat. Dapat juga dikatakan jika t hitung >t tabel maka hasilnya signifikan dan berarti $\mathrm{HO}$ ditolak dan $\mathrm{H} 1$ diterima. Sebaliknya, jika t hitung $<\mathrm{t}$ tabel maka hasilnya tidak signifikan dan berarti $\mathrm{H} 0$ diterima dan $\mathrm{H} 1$ ditolak.

Tabel 9 Hasil Uji t (Parsial)

\begin{tabular}{|r|r|r|c|c|c|}
\hline \multirow{2}{*}{ Model } & \multicolumn{2}{|c|}{$\begin{array}{c}\text { Unstandardized } \\
\text { Coefficients }\end{array}$} & $\begin{array}{c}\text { Standardized } \\
\text { Coefficients }\end{array}$ & \multirow{2}{*}{} & \multirow{2}{*}{ Sig. } \\
\cline { 2 - 4 } & $\mathrm{B}$ & $\begin{array}{c}\text { Std. } \\
\text { Error }\end{array}$ & Beta & $\mathrm{t}$ & Sig. \\
\hline Constant & 1.951 & .196 & & 9.966 & .000 \\
\hline OJT & .574 & .049 & .748 & 11.718 & .000 \\
\hline
\end{tabular}

Sumber: Data Olah Penulis 2017

\section{PEMBAHASAN \\ On The Job Training}

Berdasarkan hasil keseluruhan penelitian dari seluruh responden yang memberikan jawaban pernyataan pada variabel on the job training menyatakan setuju dengan 17 item. Hasil dari variabel on the job training adalah bahwa penyampaian program pelatihan di PT Kereta Api Indonesia (Persero) Kantor Pusat Bandung mampu meningkatkan pengetahuan dan kemampuan baru bagi karyawan unit umum \& IT, metode yang digunakan sesuai dengan kebutuhan perusahaan, tujuan perusahaan sudah mampu dicapai melalui program pelatihan dan instruktur mampu menyampaikan materi dengan baik kepada karyawan sehingga karyawan mampu mengerti apa yang menjadi harapan perusahaan yang berkaitan dengan peningkatan kualitas karyawan. 


\section{Kinerja Karyawan}

Berdasarkan hasil keseluruhan penelitian dari seluruh responden yang memberikan jawaban pernyataan pada variabel on the job training menyatakan setuju dengan 13 item. Hasil dari variabel kinerja karyawan adalah karyawan di unit Umum \& IT PT Kereta Api Indonesia mampu menyelesaikan pekerjaan sesuai dengan standar perusahaan, karyawan mampu menyelesaikan pekerjaan sesuai dengan waktu yang telah ditentukan, hasil kerja karyawan mampu melampaui hasil kerja karyawan yang lain dan karyawan mampu bekerja dengan baik tanpa adanya pengawasan dari atasan.

\section{Pengaruh On The Job Training Terhadap Kinerja Karyawan}

Berdasarkan hasil uji hipotesis yang telah dilakukan, dapat diketahui bahwa program pelatihan on the job training memiliki pengaruh yang signifikan terhadap kinerja karyawan. Hal ini dikarenakan t hitung $=11.718$. Sedangkan statistic tabel untuk taraf nyata sebesar 5\% dan derajat bebas $(n-2)=108$ maka diperoleh $\mathrm{t}(0,05.108)=1.65909$. Berdasarkan hasil tersebut dapat dilihat bahwa t hitung lebih besar dari statistic tabel (11.718 > 1.65909). Hal ini berarti H0 ditolak sehingga dapat disimpulkan bahwa kinerja karyawan dapat dipengaruhi secara signifikan oleh variabel on the job training.

\section{KESIMPULAN DAN SARAN Kesimpulan}

Program pelatihan on the job training sudah dilakukan oleh PT Kereta Api Indonesia (Persero) Kantor Pusat dengan baik. Hal ini dibuktikan oleh nilai mean dari variable on the job training berada pada skala interval yang termasuk pada kategori baik. Kemudian, dari kempat dimensi variable on the job training penyampaian program pelatihan dan tujuan pelatihan memiliki mean lebih rendah daripada mean rata-rata variable on the job training. Hasil penelitian di lapangan menunjukan bahwa program on the job training di unit Umum \& IT PT Kereta Api Indonesia (Persero) Kantor Pusat Bandung sesuai dengan fakta yang ada di lapangan.

Kinerja karyawan yang dimiliki oleh karyawan PT Kereta Api Indonesia (Persero) Kantor Pusat Bandung unit Umum \& IT sudah baik. Hal ini dibuktikan oleh nilai mean dari variable perilaku kerja karyawan pada skala interval yang termasuk pada kategori baik. Namun, dari keempat dimensi variabel kinerja karyawan terdapat dua dimensi yang berada di bawah nilai mean rata-rata variable yaitu kualitas kerja dan Need for Supervision.

On the job training mempengaruhi kinerja karyawan secara positif dan signifikan. On the job training mempengaruhi kinerja karyawan sebesar $75 \%$ dan sisanya sebanyak $25 \%$ dipengaruhi oleh variable lain yang tidak termasuk dalam penelitian ini. Kemudian, berdasarkan hasil regresi sederhana diperoleh persamaan sederhana. Dari persamaan regresi tersebut, dapat diketahui bahwa terjadi pengaruh positif dari on the job training terhadap kinerja karyawan. Hal ini berarti jika ada penambahan nilai dari on the job training maka nilai kinerja karyawan pun akan bertambah. Selain itu, dari nilai signifikansi variable diketahui adanya pengaruh signifikan antara variabel on the job training dengan kinerja karyawan.

\section{Saran}

Berdasarkan penelitian mengenai pengaruh on the job training terhadap kinerja karyawan pada unit Umum \& IT PT Kereta Api Indonesia (Persero) Kantor Pusat Bandung dengan observasi dan analisa data yang berasal dari kuesioner, penulis mengungkapkan beberapa saran dan masukan kepada perusahaan. Adapun saran atau masukan yang diberikan adalah sebagai berikut. 
Program pelatihan yang dilakukan oleh perusahaan perlu untuk dimodifikasi lagi agar semakin baik sehingga karyawan akan semakin bersemangat dan memiliki motivasi kerja yang tinggi.

Karyawan di unit Umum \& IT PT Kereta Api Indonesia (Persero) Kantor Pusat Bandung perlu meningkatkan kemampuan dan kinerja mereka dalam bekerja agar dapat mencapai target yang telah ditetapkan perusahaan.

\section{DAFTAR PUSTAKA}

Jamsari, A. B., Santhi, R. \& Mahmood, N. H. (2015). Impact of Training on Employees' Job Performance: A Case Study of Malaysian Small Medium Enterprise. Review of Management. Vol.5 No. 1/2.

Bernardin \& Russel. (2003). Human Resources Management. McGraw Hill: New York.

Darmawan, D. (2013). Metode Penelitian Kuantitatif. PT R. Bandung: Remaja Rosdakarya.

Darodjat, A. T. (2015). Manajemen Personalia - Masa Kini. Bandung: PT Refika Aditama.

Dessler, G. (2009). Manajemen Sumber Daya Manusia. Jakarta: Index.

Ghozali, I. (2013). Aplikasi Analisis Multivariate dengan program IBM SPSS 21. Semarang. Badan Penerbit Universitas Diponegoro.
Hasibuan, M. S. P. (2012). Manajemen Sumber Daya Manusia. Jakarta: PT Bumi Aksara.

Hafeez, U. (2015). Impact of Training on Employees Performance:Evidence from Pharmaceutical Companies in Karachi, Pakistan. Business Management and Strategy. Vol.6 No.1:52-54.

Mathis. A. J. (2006). Human Resource Management. Jakarta: Selemba Empat.

Noe, A. R. (2013). Employee Training \& Development (6th ed). New York: McGraw Hill International Edition.

Timpe, A. D. (2002). Seri Manajemen Sumber Daya Manusia Kinerja. Jakarta: Elex Media Komputindo.

Sekaran, U. \& Bougie, R. (2013). Research Methods for Business. United Kingdom: Jhon Wiley \& Sons Ltd.

Sugiyono. (2012). Metode Penelitian Administrasi. Bandung:Alfabeta.

Swasto, B. Manajemen Sumber Daya Manusia. Malang. Universitas Brawijaya Press (UB Press).

Widodo, E. S. (2015). Manajemen Pengembangan Sumber Daya Manusia. Yogyakarta: Pustaka Pelajar.

Zulganef. (2013). Metode Penelitian Sosial dan Bisnis. Edisi Pertama. Yogyakarta:Graha Ilmu. 